\title{
Ultra-low charge transfer resistance carbons by one- pot hydrothermal method for glucose sensing
}

\author{
Botao $\mathrm{Hu}^{1}$, Jen-Tsai Liu ${ }^{1 *}$, Ching-Jung Chen ${ }^{2 *}$, Zhan $\mathrm{Zhao}^{2,3}$, Shwu Jen Chang ${ }^{4}$ and Pei-Leun Kang ${ }^{5}$
}

\begin{abstract}
Hydrothermal carbon (HTC) is typically welldispersed, but it remains a great challenge for $\mathrm{HTC}$ to become conductive. Co-doping with heteroatoms has been confirmed to be an effective strategy to significantly promote the electrical conductivity of carbon. Moreover, there is no simple and green method to construct sensitive HTC based electrochemical biosensors until now. In this paper, $\mathrm{N}$ and $\mathrm{S}$ dualdoped carbon (NS-C) with ultra-low charge transfer resistance is easily synthesized from L-cysteine and glucose in a hydrothermal reaction system. The morphology, structural properties and electrochemical properties of the as-prepared NS-C are analyzed. In comparison with the undoped hydrothermal (UC) modified glassy carbon electrode (GCE), the charge transfer resistance of UC ( $476 \Omega)$ is ten times the value of NSC (46 $\Omega$ ). The developed biosensor shows a better performance to detect glucose in a wide concentration range (50-2500 $\left.\mu \mathrm{mol} \mathrm{L}{ }^{-1}\right)$ with the detection limit of $1.77 \mu \mathrm{mol} \mathrm{L}{ }^{-1}(\mathrm{~S} / \mathrm{N}=3)$ and a high sensitivity $\left(0.0554 \mu \mathrm{A} \mathrm{cm}^{-2} \mu \mathrm{mol}^{-1} \mathrm{~L}\right)$. The apparent Michaelis-Menten constant value of GCE/NS-C/GOx/nafion modified electrode is $0.769 \mathrm{mmol} \mathrm{L}^{-1}$, indicating a high affinity of glucose oxidase to glucose. These results demonstrate that the hydrothermal method is an effective way for preparing high electrical conductivity carbon with excellent performances in biosensor application.
\end{abstract}

Keywords: hydrothermal method, glucose biosensor, charge transfer resistance, heteroatom doped carbon, electrochemical behavior

\section{INTRODUCTION}

Carbon has many advantages such as abundant source and fine chemical stability. Carbon materials have attracted increasing attention because of its remarkable electronic [1], optical [2], mechanical [3] and catalytic $[4,5]$ properties. These characteristics make it one of the most common electrode materials applied in electrochemical sensing platforms [6,7]. Carbon based electrochemical biosensors have been extensively used in many hot fields such as environmental analysis, food industry and clinical testing because of their unique electrochemical properties [7].

Recently, many investigations have been focused on finding a simple, green and low toxic process to synthesize carbon materials with excellent electrical properties. The chemical vapor deposition (CVD) method [8], template method [9], arc discharge method [10] and high temperature pyrolysis method [11] to produce carbon materials normally rely on very harsh and multistep processes, and a large consumption of energy and many chemical sources. By comparison, hydrothermal synthetic approach is a green [12], non-toxic, cheap and sustainable way to obtain carbon materials from biomass $[13,14]$. The hydrothermal carbon (HTC) products synthesized in comparatively mild condition are mostly disordered amorphous carbon, resulting in poor conductivity $[14,15]$ and large electron transfer resistance. Although many researches have been focused on the field of fluorescence because of abundant functional groups on the carbon surface [2], a few studies have used HTC to fabricate electrochemical sensors. For example, graphene-multiwalled carbon nanotubes composite (G-MWCNTs) [16] was prepared by an in situ hydrothermal process and the molecularly imprinted polymer and G-MWCNTs modified glassy carbon electrode (GCE) was investigated for rutin sensing. The linear response range was $0.01-1.0$ $\mu \mathrm{mol} \mathrm{L}{ }^{-1}$ and the detection limit was $0.005 \mu \mathrm{mol} \mathrm{L}{ }^{-1}$ at a

\footnotetext{
${ }^{1}$ College of Materials Science and Opti-Electronic Technology, University of Chinese Academy of Sciences, Beijing 101408

${ }^{2}$ School of Electronic, Electrical and Communication Engineering, University of Chinese Academy of Sciences, Beijing 101408

${ }^{3}$ State Key Lab of Transducer Technology, Institute of Electronics, Chinese Academy of Sciences, Beijing 100089

${ }^{4}$ Department of Electric Engineering, I-Shou University, Kaohsiung 82445

${ }^{5}$ Cardiovascular Surgery, Department of Surgery, Kaohsiung Veterans General Hospital, Kaohsiung 82445

* Corresponding authors (emails: jtliu@ucas.ac.cn (Liu JT); cjchen@ucas.ac.cn (Chen CJ))
} 
signal-to-noise ratio of 3. The hydrothermal method was also used for synthesis of graphene quantum dots (GQD). The response of the developed biosensor to glucose was observed in the range of $5-1270 \mu \mathrm{mol} \mathrm{L}^{-1}$, and the detection limit was calculated to be $1.73 \mu \mathrm{mol} \mathrm{L}{ }^{-1}$ with a sensitivity of $0.085 \mu \mathrm{A} \mathrm{cm}{ }^{-2} \mu \mathrm{mol}^{-1} \mathrm{~L}$ [17]. By contrast with graphene nanosheets modified GCE electrode [18] and acetylene black modified GCE electrode [19], the HTC based electrodes have less unbound electron, larger transfer resistance in the electrochemical impedance spectra and result in poor sensitivity when applied in biosensors [20]. Thus, enhancing electron transfer of HTC is one of the most important issues.

In the previous studies, researchers have attempted to improve the electrical conductivity of carbon materials by chemical doping [21-26] and increased crystallized graphene structure [27], such as using $\mathrm{H}_{2} \mathrm{SO}_{4}$ to strip off $\mathrm{O}$ and $\mathrm{H}$ from the $\mathrm{C}-\mathrm{OH}, \mathrm{C}-\mathrm{H}$, and $\mathrm{C}=\mathrm{O}$ groups, to form the electro-conductive graphite structure; however, the effect is limited. Several studies have shown that doping carbon materials with heteroatoms (nitrogen, boron, sulfur and phosphorous) is a promising way to further improve the electrical conductivity [21-26], such as doping nitrogen into carbon to form pyridine- $\mathrm{N}$, pyrrole$\mathrm{N}$ and graphitic- $\mathrm{N}$ structure. These donating electron structures can form enhanced $\pi$-bonding to promote electron transfer [28,29] which is advantageous for enhancing electrochemical sensing performances [30]. Wang et al. [31] reported a glucose sensor based on $\mathrm{N}$ doped graphene $(\mathrm{N}-\mathrm{G})$ by using nitrogen plasma treatment of graphene, and the results showed that the $\mathrm{N}$ doped graphene modified glucose oxidase (GOx) electrode displayed a high electrocatalytic activity for reduction of $\mathrm{H}_{2} \mathrm{O}_{2}$ with high sensitivity and selectivity for glucose sensing. Ji et al. [32] obtained N-doped carbon dots synthesised from polyacrylamide. The $\mathrm{N}$-doped carbon dots showed strong electrocatalysis to the reduction of $\mathrm{O}_{2}$ and the $\mathrm{N}$-doped carbon dots based biosensor responded efficiently to glucose at the concentration range of 1 to $12 \mathrm{mmol} \mathrm{L}^{-1}$ with a detection limit of $0.25 \mathrm{mmol} \mathrm{L}^{-1}$.

Similar to nitrogen, sulfur doping can also improve electron conductivity [22,33]. N and S co-doping has been confirmed to be an effective strategy to significantly promote the electrocatalytic activity of carbon. Chen et al. [22] synthesized N and S dual-doped graphene (NS-G) using a simple two-step solvothermal method. The dualdoping of $\mathrm{N}$ and $\mathrm{S}$ in carbon not only modulated its electrical properties, but also introduced active sites by the doping heteroatoms [34]. Comparing GOx/N-G/GCE with GOx/NS-G/GCE, the latter showed a lower detect limit, a wider detection range, and a higher sensitivity towards glucose detection. Tian et al. [35] used a one-step and low cost microwave-assisted solvothermal approach to synthesize NS-G (N: 6.8 at.\%, S: 2.1 at.\%). The NS-G was then evaluated as an electrocatalyst for $\mathrm{H}_{2} \mathrm{O}_{2}$ reduction and exhibited a higher electrochemical performance than its undoped or mono-doped counterparts due to the synergistic effect of $\mathrm{N}, \mathrm{S}$ co-doping. But solvothermal synthesis involves organic solvents, and it is not suitable for fabricating biocompatible electrodes for enzyme immobilization [36]. The procedure of hydrothermal method, however, is green and non-toxic, making it a better choice for fabricating biocompatible electrodes.

Considering the aforementioned merits, we proposed a simple and green one-step hydrothermal method to synthesize $\mathrm{N}$ and $\mathrm{S}$ dual-doped carbon by using glucose as the sustainable precursor and L-cysteine as the N/S source. To explore the structural and surface properties of NS-C, the morphology, crystal and chemical structure characterizations were carried out. The electrochemical behaviors of the NS-C modified electrodes were further characterized by cyclic voltammograms (CV), chronoamperometry (CA) and electrochemical impedance spectroscopy (EIS). The electrochemical performance of the NS-C modified electrode was compared with undoped carbon (UC), and the NS-C as a GOx platform was examined as a sensitive glucose biosensor.

\section{EXPERIMENTAL SECTION}

\section{Chemicals and reagents}

Glucose oxidase was obtained from Sigma Chemical (USA), and the solution was prepared in $0.1 \mathrm{~mol} \mathrm{~L}^{-1}$ phosphate buffer solution (PBS) with $\mathrm{pH} 7.4$ and stored at $4^{\circ} \mathrm{C}$ before use. Glucose, concentrated sulfuric acid $\left(\mathrm{H}_{2} \mathrm{SO}_{4}\right)$, sodium hydroxide, $\mathrm{K}_{3}\left[\mathrm{Fe}(\mathrm{CN})_{6}\right], \mathrm{K}_{4}\left[\mathrm{Fe}(\mathrm{CN})_{6}\right]$ and L-cysteine were purchased from Beijing Chemical Reagent Co., Ltd. Deionized water $\left(18.2 \mathrm{M} \Omega \mathrm{cm}^{-1}\right)$ was obtained from an Explorer Series ultrapure water purification system (Explorer Technic Co., Ltd., China). All other chemical reagents were analytical grade and used without purification.

\section{Synthesis of NS-C}

$\mathrm{N}$ and $\mathrm{S}$ dual-doped carbon was prepared through a onestep hydrothermal method by using glucose, L-cysteine and sulfuric acid (Fig. 1a). L-cysteine acts as a functionalization agent to provide the source for $\mathrm{N}$ and $\mathrm{S}$ doping. Fig. 1a shows pyridinc-N, pyrrolic-N, and graphitic-N in 

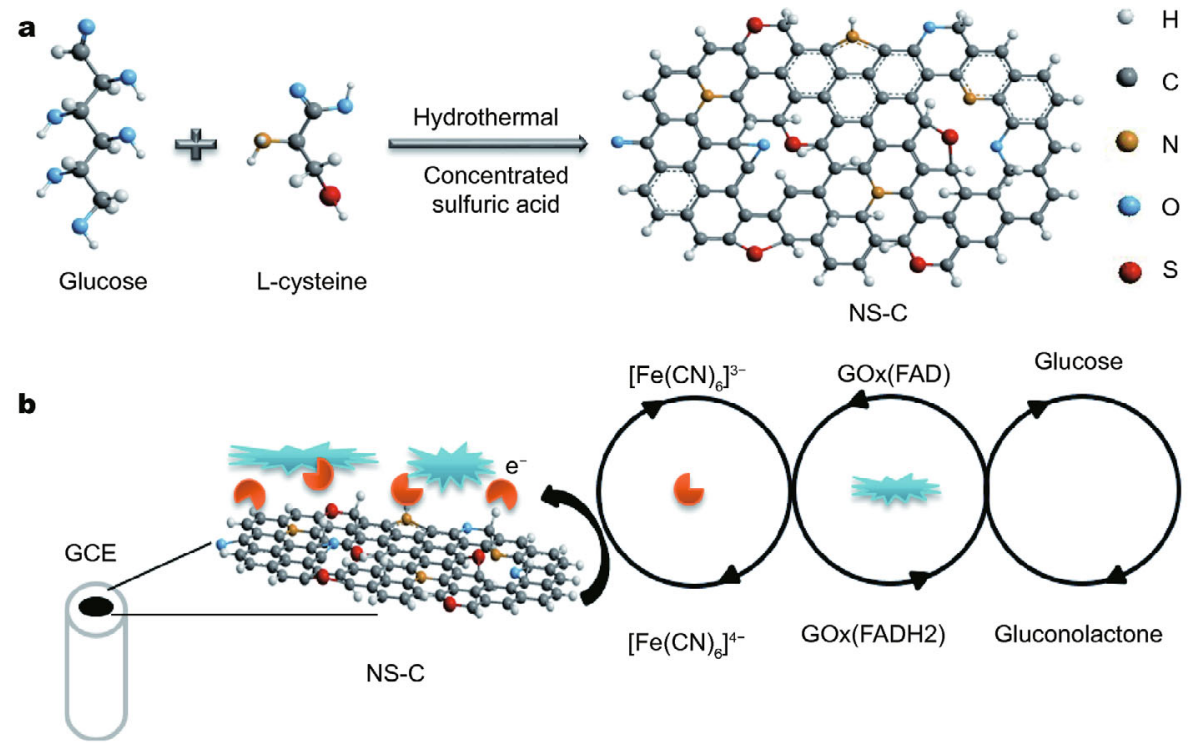

Figure 1 Schematic representation of the synthesis route of NS-C (a) and the GCE/NS-C/GOx/nafion modified electrode and the mechanism of the oxidation of glucose (b), catalyzed by $\mathrm{GOx}$ and mediated by $\left[\mathrm{Fe}(\mathrm{CN})_{6}\right]^{3-/ 4-}$.

the carbon structure. The amine and thiol group of $\mathrm{L}$ cysteine can react with the aldehyde group of the glucose. These so-called Maillard reactions play a major role in the incorporation of heteroatoms during HTC [28,29]. Briefly, $1.5 \mathrm{~g}$ of glucose and $0.4 \mathrm{~g}$ of L-cysteine or its derivative were dissolved in $10 \mathrm{~g}$ of double distilled $\mathrm{H}_{2} \mathrm{O}$, followed by the introduction of $10 \mathrm{~mL}$ of concentrated sulfuric acid $\left(\mathrm{H}_{2} \mathrm{SO}_{4}\right)$. The mixture was then treated by the hydrothermal method in Teflon-lined stainless-steel autoclave $(50 \mathrm{~mL})$. The autoclave was placed in a preheated furnace at $180^{\circ} \mathrm{C}$ for $5 \mathrm{~h}$, after which it was allowed to cool down to room temperature. The brown/black solid product was collected by filtration and neutralized with sodium hydroxide. The samples were washed several times by water and ethanol, and dried at $70^{\circ} \mathrm{C}$ overnight for further characterization.

\section{Preparation of NS-C/GOx modified GCE}

The GCE (3 $\mathrm{mm}$ in diameter) was polished with polishing paper and alumina/water slurry. Then it was rinsed with double distilled water and ethanol. $5 \mu \mathrm{L}$ of NS-C solution $\left(5 \mathrm{mg} \mathrm{mL}^{-1}\right.$ ) was cast on the surface of GCE and dried at $60^{\circ} \mathrm{C}$ to obtain a homogeneous NS-C film. Then $5 \mu \mathrm{L}$ of GOx suspension $\left(0.5 \mathrm{mg} \mathrm{mL}^{-1}\right)$ was cast onto the NS-C/ GCE surface to prepare the NS-C/GOx modified GCE. Finally, $5 \mu \mathrm{L}$ nafion solutions $\left(0.5 \mathrm{mg} \mathrm{mL}^{-1}\right)$ was cast onto the electrode surface and dried at ambient temperature to produce the GCE/NS-C/GOx/nafion. The electrode was stored at $4^{\circ} \mathrm{C}$ when not in use.
Surface morphology and composition analysis

The morphologies of the as-prepared samples were studied by scanning electron microscopy (SEM, Hitachi S4800, Japan) and transmission electron microscopy (TEM, Tecnai G2T20, USA). The phase identification of the sample was characterized by X-ray diffraction (XRD, Persee XD-3, China). The XRD equipped with $\mathrm{Cu} \mathrm{Ka}$ radiation source was in the range from $10^{\circ}-60^{\circ}$ (the scan speed is $2^{\circ} \mathrm{min}^{-1}$ ). The chemical status of elements were investigated by X-ray photoelectron spectroscopy (XPS, Thermo ESCALAB 250Xi, USA), which used Mg Ka radiation as the exciting source. Further structural information of carbon materials was obtained from Raman spectroscopy (Renishaw inVia plus, UK).

\section{Electrochemical measurements}

NS-C as a GOx platform for the construction of GOxbased glucose biosensor is illustrated by Fig. 1b. The electrochemical experiments were carried out using an electrochemical analyser (CHI660E, Shanghai) at room temperature. The three-electrode system is composed of reference electrode, auxiliary electrode and working electrode, in which $\mathrm{Ag} / \mathrm{AgCl}$ electrode as the reference electrode, platinum wire as the auxiliary electrode and the prepared electrode as the working electrode. The electrochemical behaviors of the modified electrodes were further investigated by CV, EIS and CA. The basic study of electrode modification was carried out using $\mathrm{CV}$ at a scan rate of $50 \mathrm{mV} \mathrm{s}^{-1}$ with a potential range of -0.8 to 

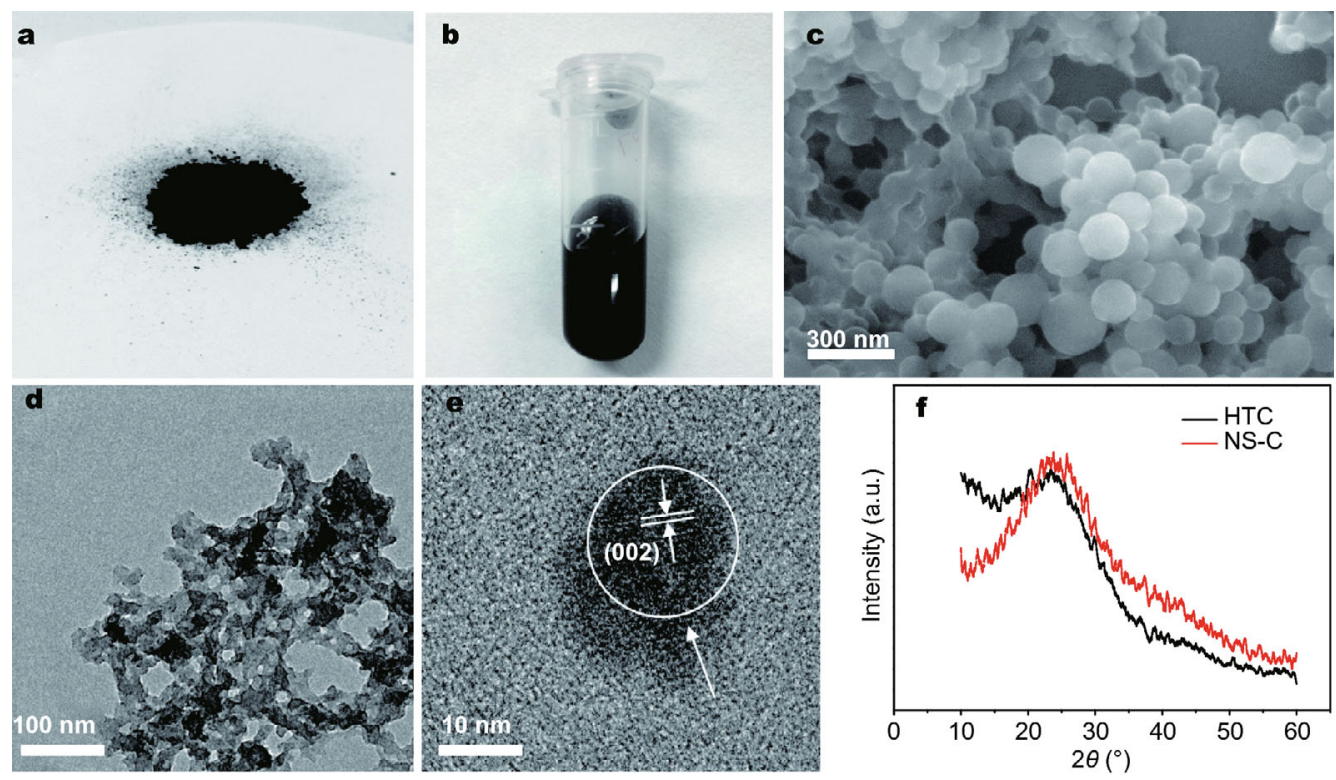

Figure 2 Images of the NS-C solid products (a) and after dispersed in water (b), SEM of solid products after hydrothermally treated pure glucose (c), TEM (d) and HRTEM (e) of NS-C, and XRD patterns of HTC and NS-C (f).

$+0.8 \mathrm{~V}$. EIS was performed in $0.1 \mathrm{~mol} \mathrm{~L}^{-1} \mathrm{KCl}$ solution containing $5 \mathrm{mmol} \mathrm{L}^{-1} \mathrm{~K}_{3}\left[\mathrm{Fe}(\mathrm{CN})_{6}\right] / \mathrm{K}_{4}\left[\mathrm{Fe}(\mathrm{CN})_{6}\right](1: 1)$ as a supporting electrolyte at its open circuit potential with a frequency range from $1.0 \times 10^{-1}$ to $1.0 \times 10^{-5} \mathrm{~Hz}$. The alternating current voltage was $5 \mathrm{mV}$. CA was used for the measurement of different concentrations of glucose solution. The initial potential was $0.3 \mathrm{~V}$, each with a duration time of $50 \mathrm{~s}$.

\section{RESULTS AND DISCUSSION}

\section{Morphologies and structures of NS-C}

A photograph of the black solid products is shown in Fig. $2 a$, and the yield of solid products is $48 \%$. The solid products could be dispersed in distilled water and result in the black suspension (Fig. 2b). Fig. 2c shows homogeneous carbon spheres with a very narrow size distribution. The formation of monodisperse particles can be explained by the widely cited LaMer model in colloid chemistry [14]. Fig. 2d displays a TEM image of solid products after hydrothermal carbonization of glucose with L-cysteine and $\mathrm{H}_{2} \mathrm{SO}_{4}$. The morphology exhibits a matrix comprising interconnected irregular particles with a size range of $10-30 \mathrm{~nm}$. This change in morphologies can be understood by additional reactants which can affect the nucleation process. Amino acid and concentrated sulfuric acid may break the seeding stage to form the carbon spheres. In the presence of $\mathrm{H}_{2} \mathrm{SO}_{4}$, the crystallinity of carbon is obviously observed in a high-resolution TEM
(HRTEM) image, as shown in Fig. 2e. The lattice spacing of $0.33 \mathrm{~nm}$ is coincident with the (002) diffraction plane of graphite carbon.

The phases of all products were investigated by powder XRD. XRD spectra of NS-C and HTC are shown in Fig. $2 \mathrm{f}$, the broad peaks centered at $26^{\circ}$ for all products can be indexed as (002) diffraction planes of the graphite (JCPDS No. 41-1487), which validates the partially graphitized nature both in the HTC and NS-C products.

The chemical composition of the NS-C sample was analyzed by XPS, and the survey-scan XPS spectrum is shown in Fig. S1 (Supplementary information). The peaks at binding energies of 284.6, 532.8, 400.1, 163.5 and $224.8 \mathrm{eV}$ are assigned to $\mathrm{C} 1 \mathrm{~s}, \mathrm{O} 1 \mathrm{~s}, \mathrm{~N} 1 \mathrm{~s}, \mathrm{~S} 2 \mathrm{p}$ and S $2 \mathrm{~s}$, respectively, and the detailed element compositions obtained by element analysis are: S $6.43 \%, \mathrm{C} 70.80 \%, \mathrm{~N}$ $2.44 \%$, and O $20.33 \%$, respectively, indicating that the sulfur and nitrogen elements exist in NS-C. The doping species of NS-G are further studied by the high-resolution XPS spectra, as shown in Fig. 3b, c. High-resolution N 1s spectrum (Fig. 3a) can be fitted into three kinds of $\mathrm{N}$ species: pyridinc-N $(398.6 \mathrm{eV})$, pyrrolic-N $(400.2 \mathrm{eV})$, and graphitic- $\mathrm{N}(401.3 \mathrm{eV})$ [37-40], indicating that the incorporated $\mathrm{N}$ atoms are mainly bonded with $\mathrm{C}$ atoms at the edges and defects of carbon (pyridinic- $\mathrm{N}$ ), three adjacent carbons within the hexagonal ring of graphene (graphitic-N) and carbons within the pentagon ring of graphene pyrrolic- $\mathrm{N}$. The existence of pyridinic-N, pyrrolic- $\mathrm{N}$ and graphitic- $\mathrm{N}$ helps to improve the electro- 

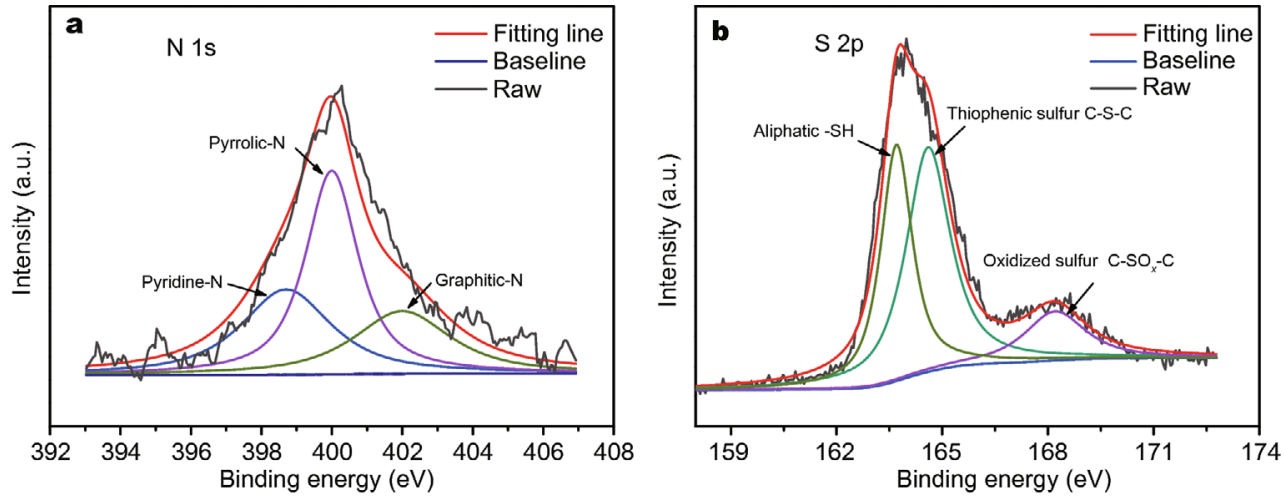

Figure 3 High-resolution XPS spectra of N 1s (a) and S 2p (b) of NS-C.

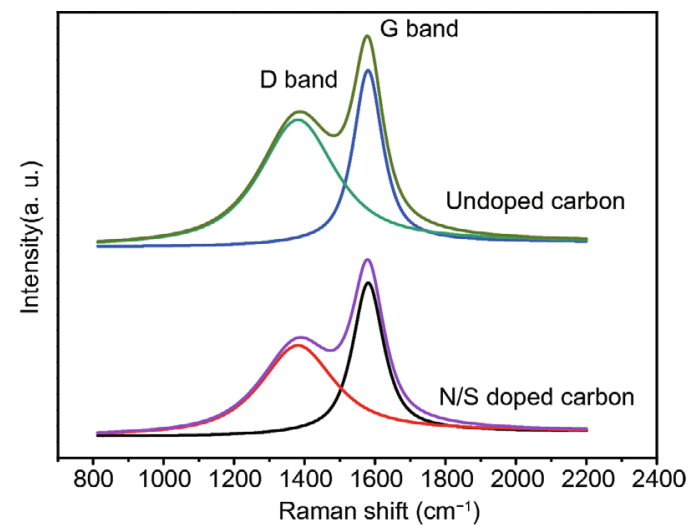

Figure 4 Raman spectra of the undoped carbon and doped carbon.

chemical activity [41]. High-resolution S 2p spectrum can be fitted into three peaks (Fig. 3b), in which the two intense peaks at 163.9 and $164.8 \mathrm{eV}$ are assigned to the $\mathrm{S}$ $2 p_{3 / 2}$ and $S 2 p_{1 / 2}$ positions of thiophene-S owing to their spin-orbit coupling [42]. The weak and broad peak at $168.7 \mathrm{eV}$ corresponds to oxidized-S $\left(-\mathrm{C}-\mathrm{SO}_{x}-\mathrm{C}-\right)$. The large portion of thiophene-S $(42.7 \%)$ indicates the incorporated $\mathrm{S}$ atoms are mainly bonded with two $\mathrm{C}$ atoms. Doping $\mathrm{S}$ in the NS-C can positively modify the catalytic properties as reported for some S-doped materials $[43,44]$. Overall, XPS analysis verified that using L-cysteine as additive results in successful incorporation of nitrogen and sulfur into the carbon frameworks.

Further, Raman spectroscopy was used to characterize the structures of carbon in NS-C and UC, as shown in Fig. 4. Two dominant peaks around 1590 and $1370 \mathrm{~cm}^{-1}$ correspond to the G- and D-bands of carbon samples in Fig. 4. The G-band can be used to characterize the $\mathrm{sp}^{2}$ bond structure of carbon atoms, and the $\mathrm{D}$ band is related to the breaking of the symmetry caused by structural disorder and defects. The relative intensity ratio of the Dband to the G-band $\left(I_{\mathrm{D}} / I_{\mathrm{G}}\right)$ is directly proportional to the amount of structural disorder in carbon $[45,46]$. The UC is hydrothermally treated glucose by $\mathrm{H}_{2} \mathrm{SO}_{4}$ but without L-cysteine. The $I_{\mathrm{D}} / I_{\mathrm{G}}$ of $\mathrm{UC}$ is estimated to be 1.421 , which shows a high graphitization degree. The $I_{\mathrm{D}} / I_{\mathrm{G}}$ value of the doped carbon (1.888) is higher than that of UC, owing to the defects in the carbon framework and the disorder of the materials introduced by the sulfur and nitrogen atoms doped in carbon $[45,46]$.

\section{EIS and CV characterizations of the modified electrodes}

EIS has been proved to be an effective tool for probing the interfacial properties like the charge transfer and charge separation processes occurring in electrochemical systems $[47,48]$. It is also an effective method to measure the biosensors because of its specificity, simplicity and high sensitivity in monitoring the interfacial electron-transfer features of the redox probe in the solution at the electrode interfaces [49]. In the Nyquist plot of a typical EIS spectrum, there are a semicircle part at higher frequency region and a straight sloping line at lower frequency region. The charge transfer resistance $\left(R_{\mathrm{ct}}\right)$ can be calculated by the semicircle diameter of the EIS at the high frequency region. Herein, EIS is employed to investigate the $R_{\mathrm{ct}}$ of $\left[\mathrm{Fe}(\mathrm{CN})_{6}\right]^{3-/ 4-}$ as a redox probe at the surface of GCE, GCE/NS-C/nafion, GCE/UC/nafion and GCE/NS$\mathrm{C} / \mathrm{GOx} /$ nafion.

It can be seen that bare GCE exhibits an almost straight line (Fig. 5a, black dot line), which indicates a diffusion limiting step of the electrochemical processes [50]. When the bare GCE is covered with nafion, the slope of GCE/ nafion (Fig. 5a, pink dot line) is higher than that of GCE, confirming that the diffusion resistance of GCE/nafion is larger than that of bare GCE [51]. However, when NS-C is assembled on the surface of GCE, the $R_{\mathrm{ct}}$ of the GCE/ 

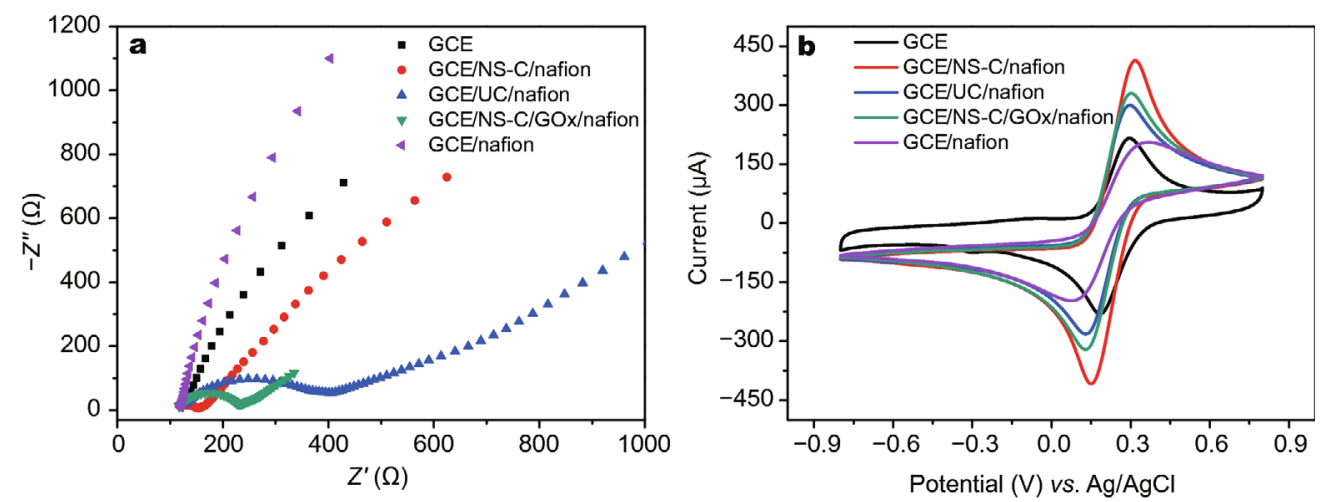

Figure 5 (a) EIS of bare GCE, GCE/NS-C/nafion, GCE/UC/nafion, GCE/NS-C/GOx/nafion, and GCE/nafion in $0.1 \mathrm{~mol} \mathrm{~L}^{-1} \mathrm{KCl}$ solution containing $5.0 \mathrm{mmol} \mathrm{L}^{-1}\left[\mathrm{Fe}(\mathrm{CN})_{6}\right]^{3-/ 4-}$; (b) CVs of bare GCE, GCE/NS-C/nafion, GCE/UC/nafion, GCE/NS-C/GOx/nafion, and GCE/nafion in $0.1 \mathrm{~mol} \mathrm{~L}{ }^{-1} \mathrm{KCl}$ solution containing $50 \mathrm{mmol} \mathrm{L}^{-1}\left[\mathrm{Fe}(\mathrm{CN})_{6}\right]^{3-14-}$.

Table 1 Electrochemical properties of different examined electrodes

\begin{tabular}{cccc}
\hline Electrodes & $\Delta E_{\mathrm{p}}(\mathrm{V})$ & $I_{\mathrm{pa}}(\mu \mathrm{A})$ & $I_{\mathrm{pc}}(\mu \mathrm{A})$ \\
\hline GCE & 0.111 & 218.8 & -226.7 \\
GCE/nafion & 0.275 & 208.1 & -199.1 \\
GCE/NS-C/nafion & 0.163 & 419.1 & -413.3 \\
GCE/UC/nafion & 0.169 & 297.4 & -218.2 \\
GCE/NS-C/GOx/nafion & 0.174 & 333.2 & -324.0 \\
\hline
\end{tabular}

NS-C/nafion is $46 \Omega$ (Fig. 5a, red dot line). Comparing with that of GCE, it suggests that the presence of NS-C can effectively promote the interfacial electron transport of the redox probe to electrode.

Moreover, the $R_{\mathrm{ct}}$ of GCE/UC/nafion (Fig. 5a, blue dot line) is $476 \Omega$, ten times of that of NS-C, which suggests that the NS-C is more favorable for interfacial electron transfer of the redox probe and has a faster electron transfer rate [17]. This can be possibly explained by that the additional N/S-doping in NS-C creates asymmetrical spin and charge density owing to the synergetic effect of $\mathrm{N}$ and $\mathrm{S}$ atoms [50], which further facilitates the interfacial electron transfer of the redox probe to electrode. When GOx is modified on the surface of GCE, the GCE/ NS-C/GOx/nafion exhibits a significant increase of resistance $\left(R_{\mathrm{ct}}=132 \Omega\right)$ due to the fact that GOx adsorbed on the GCE hinders the electron exchange between the electrochemical probe and the NS-C [52].

In order to better clarify the different electrochemical response of NS-C modified electrode, some derived features from $\mathrm{CV}$ of $\left[\mathrm{Fe}(\mathrm{CN})_{6}\right]^{3-14-}$ are compared (Fig. $5 \mathrm{~b}$ ). It can be observed in the Table 1 that the GCE/NS-C/nafion electrode exhibits the lowest value of $\Delta E_{\mathrm{p}}(163 \mathrm{mV})$ and the highest redox peak current intensity compared with GCE/UC/nafion and GCE/NS-C/GOx/nafion, which in- dicates the NS-C facilitates the electron transfer [53] $\left(\Delta E_{\mathrm{p}}=E_{\mathrm{pox}}-E_{\mathrm{pred}}\right.$, where $E_{\mathrm{pox}}$ and $E_{\mathrm{pred}}$ are the corresponding peak potentials for oxidation and reduction, respectively).

Electrochemical behavior of the modified electrode As shown in Fig. 6, the CVs of both GCE/NS-C/nafion (Fig. 6a) and GCE/NS-C/GOx/nafion (Fig. 6b) electrodes show different scan rates. Fig. 6a shows that the redox peak currents increase linearly with scan rate. The plot of peak current versus scan rate shows a good linear relationship, which reveals that the electrochemical behavior of electrode has a typical property of surface process (inset of Fig. 6a). The linear regression equations can be expressed by $I_{\mathrm{pa}}(\mu \mathrm{A})=3540 v\left(\mu \mathrm{A} \mathrm{V} \mathrm{V}^{-1}\right)+252\left(R^{2}=0.985\right)$ for anodic current, and $I_{\mathrm{pc}}(\mu \mathrm{A})=-3450 v\left(\mu \mathrm{A} \quad \mathrm{V}^{-1}\right)-273$ $\left(R^{2}=0.986\right)$ for cathodic current, where $v$ is the scan rate. This indicates a fast electron transfer between NS-C and electrode. Fig. $6 \mathrm{~b}$ shows the influence of the scan rate of GCE/NS-C/GOx/nafion electrode. Both the anodic and cathodic peak currents increase linearly with the square root of scan rate $\left(v^{1 / 2}\right)$, which infers that the redox behavior of the electrodes is diffusion controlled. The main reason of the difference between GCE/NS-C/nafion and GCE/NS-C/GOx/nafion electrodes is the electron transfer from the redox centers of the GOx to NS-C involved a diffusion process [54].

\section{Electrochemical response of GCE/NS-C/GOx/nafion modified electrode to glucose}

The electrocatalytic behavior of the as-prepared biosensor on glucose oxidation was further investigated by $\mathrm{CV}$ in $\left[\mathrm{Fe}(\mathrm{CN})_{6}\right]^{3-/ 4-}\left(50 \mathrm{mmol} \mathrm{L}^{-1} ; \mathrm{pH}\right.$ 7.0). Fig. 7 displays the relation between the reduction peak current of GCE/NS- 

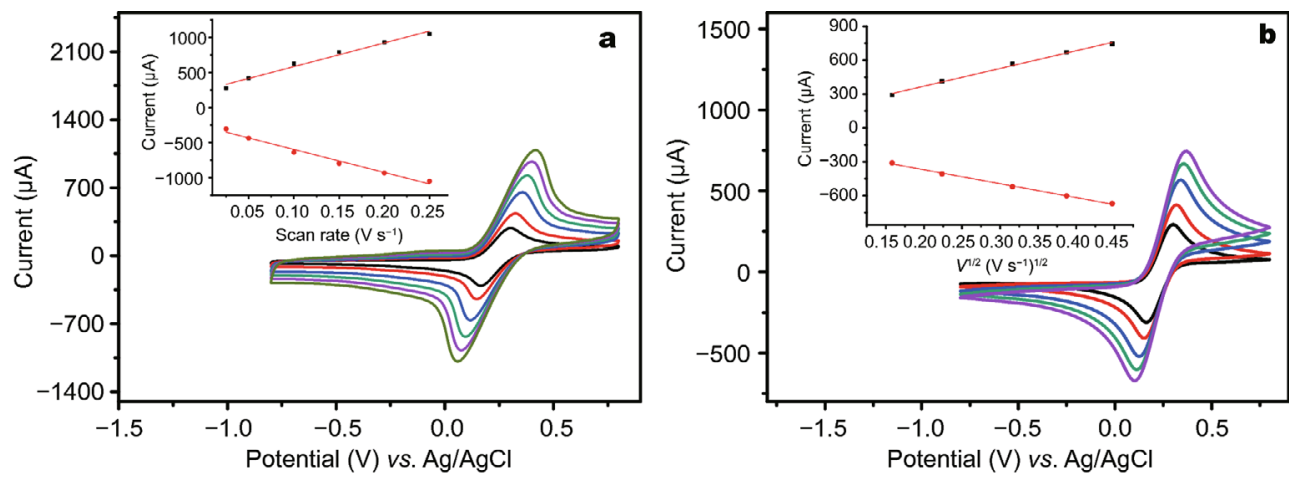

Figure 6 (a) CVs of GCE/NS-C/nafion modified electrode in $50 \mathrm{mmol} \mathrm{L}^{-1}\left[\mathrm{Fe}(\mathrm{CN})_{6}\right]^{3-/ 4-}\left(\mathrm{pH} 7.0\right.$, containing $\left.0.1 \mathrm{~mol} \mathrm{~L}^{-1} \mathrm{KCl}\right)$ at different scan rates (from inner to outer: 25, 50,100,150, 200, $250 \mathrm{mV} \mathrm{s}^{-1}$ ). Inset: plots of peak current $v s$. scan rate; (b) GCE/NS-C/GOx/nafion modified electrode in $50 \mathrm{mmol} \mathrm{L}^{-1}\left[\mathrm{Fe}(\mathrm{CN})_{6}\right]^{3-/ 4-}\left(\mathrm{pH} 7.0\right.$, containing $\left.0.1 \mathrm{~mol} \mathrm{~L}^{-1} \mathrm{KCl}\right)$ at different scan rates (from inner to outer: 25, 50,100, 150, $\left.200 \mathrm{mV} \mathrm{s}{ }^{-1}\right)$. Inset: plots of peak current $v$ s. $v^{1 / 2}$.

C/GOx/nafion modified electrode and different concentrations of glucose. With the increase of glucose concentration in solution, the $\mathrm{CV}$ of the GCE/NS-C/ GOx/nafion modified electrode shows an increased anodic peak current combined with a decreased cathodic peak current (inset of Fig. 7), which suggests an evident electrocatalytic oxidation of glucose in $\left[\mathrm{Fe}(\mathrm{CN})_{6}\right]^{3-/ 4-}$. The enzyme catalytic mechanism of glucose oxidation is proposed as follows:

$$
\text { GOx }(\mathrm{FAD})+\text { glucose } \rightarrow \text { GOx(FADH2) }
$$

+ gluconolactone,

$$
\begin{aligned}
& {\left[\mathrm{Fe}(\mathrm{CN})_{6}\right]^{3-}+\mathrm{GOx}(\mathrm{FADH} 2) \rightarrow\left[\mathrm{Fe}(\mathrm{CN})_{6}\right]^{4-}} \\
& +\mathrm{GOx}(\mathrm{FAD}), \\
& {\left[\mathrm{Fe}(\mathrm{CN})_{6}\right]^{4-} \rightleftharpoons \mathrm{e}^{-}+\left[\mathrm{Fe}(\mathrm{CN})_{6}\right]^{3-} .}
\end{aligned}
$$

When the concentration of glucose is higher than $1.5 \mathrm{mmol} \mathrm{L}^{-1}$, the electrode response deviates from linearity and levels off, showing the characteristics of the Michaelis-Menten kinetic mechanism. The apparent Michalis-Menten constant $\left(K_{\mathrm{m}}^{\text {app }}\right)$ ， an indicator of enzymesubstrate reaction kinetic, can be used to evaluate the biological activity of the immobilized enzyme. It can be obtained from the Lineweaver-Burk equation as follows [55]:

$$
\frac{1}{I_{\mathrm{ss}}}=\frac{1}{I_{\max }}+\frac{K_{\mathrm{m}}}{I_{\max }} \frac{1}{C}
$$

where $I_{\mathrm{ss}}$ is the steady state current (background current deducted) after the addition of substrate, $C$ is the concentration of glucose in electrochemical systems, and $I_{\max }$ is the maximum current measured under saturated substrate conditions. $K_{\mathrm{m}}$ can be calculated by the slope and

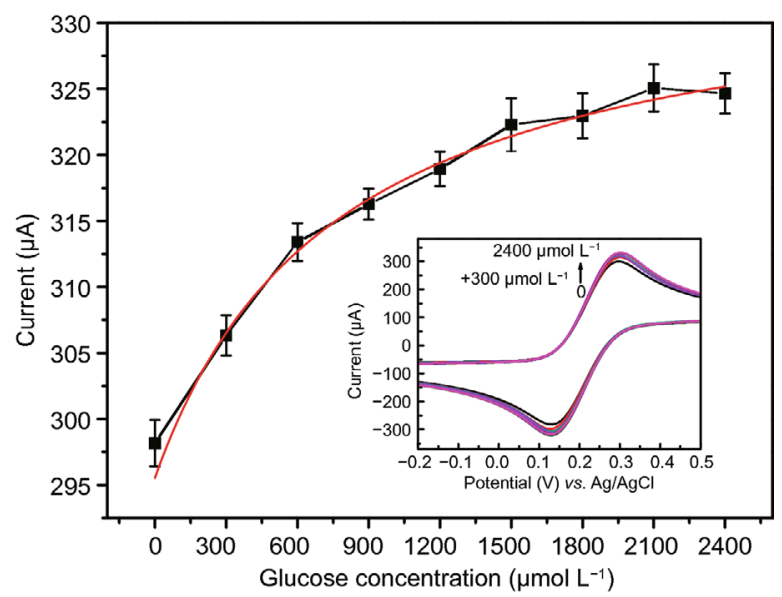

Figure 7 The calibration plot of the current versus the glucose concentration. Inset: $\mathrm{CVs}$ of the GCE/NS-C/GOx/nafion modified electrode to glucose in $\left[\mathrm{Fe}(\mathrm{CN})_{6}\right]^{3-/ 4-}\left(50 \mathrm{mmol} \mathrm{L}^{-1} ; \mathrm{pH} 7.0\right)$ at a scan rate of $50 \mathrm{mV} \mathrm{s}^{-1}$.

the intercept of the plot in Fig. 7 according to the Lineweaver-Burk equation.

Here, the equation: $I_{\mathrm{p}}=296+39 C_{\mathrm{Glu}} /\left(769+C_{\mathrm{Glu}}\right)\left(I_{\mathrm{p}}: \mu \mathrm{A}\right.$, $\left.C_{\text {Glu }}: \mu \mathrm{mol} \mathrm{L} \mathrm{L}^{-1}, R^{2}=0.981\right)$ fits for the plot of the current versus the glucose concentration. The $K_{\mathrm{m}}^{\mathrm{app}}$ value of GCE/ NS-C/GOx/nafion modified electrode is estimated to be $0.769 \mathrm{mmol} \mathrm{L}^{-1}$, which is smaller than those of $\mathrm{GOx} /$ CNx-MWNTs $\left(2.2 \mathrm{mmol} \mathrm{L}^{-1}\right)$ [53], CS-Fc/GO/GOx $\left(2.1 \mathrm{mmol} \mathrm{L}^{-1}\right) \quad[54], \quad$ GOD/MWNTs/CS-Fc $\quad(6.87$ $\mathrm{mmol} \mathrm{L}^{-1}$ ) [56]. The lower magnitude of $K_{\mathrm{m}}$ confirms the retention of GOx native structure in GCE/NS-C/GOx/ nafion, which results in higher affinity and activity of the GOx to the glucose in an enzymatic reaction. The results indicate that the $\mathrm{N}$ and $\mathrm{S}$ dual-doped hydrothermal car- 

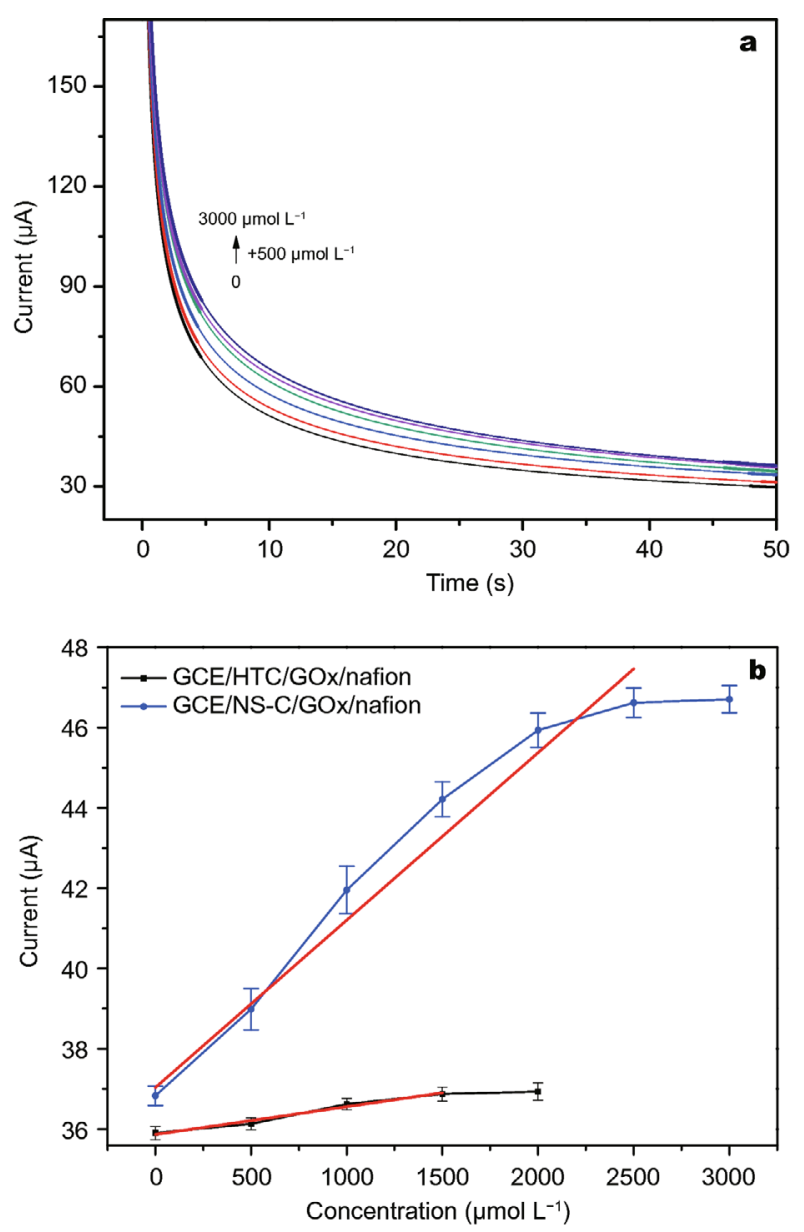

Figure 8 (a) Chronoamperograms of glucose assay based on the GCE/ NS-C/GOx/nafion modified electrode in $\left[\mathrm{Fe}(\mathrm{CN})_{6}\right]^{3-/ 4-}\left(50 \mathrm{mmol} \mathrm{L}^{-1}\right.$; $\mathrm{pH} 7.0$ ); (b) the corresponding linear calibration curve of current versus glucose concentration.

bon is more suitable for enzyme immobilization.

By employing the optimum conditions studied before, the CA measurements of the GCE/NS-C/GOx/nafion modified electrode for different glucose solution are obtained and shown in Fig. 8a. The current response time is $40 \mathrm{~s}$, which indicates a fast response for detecting glucose. Fig. $8 \mathrm{~b}$ shows the calibration curve of GCE/HTC/GOx/ nafion and GCE/NS-C/GOx/nafion modified electrode for glucose detection $(n=3)$. The linear regression equation of GCE/NS-C/GOx/nafion and GCE/HTC/GOx/nafion is $I_{\mathrm{p}}=37.5+0.00393 C_{\mathrm{Glu}}\left(R^{2}=0.965\right)$ and $I_{\mathrm{p}}=35.8$ $+0.00071 C_{\mathrm{Glu}}\left(R^{2}=0.995, I_{\mathrm{p}}: \mu \mathrm{A}, C_{\mathrm{Glu}}: \mu \mathrm{mol} \mathrm{L}{ }^{-1}\right)$, respectively. The detection range of GCE/NS-C/GOx/nafion is $50-2500 \mu \mathrm{mol} \mathrm{L}{ }^{-1}$, which is wider than that of GCE/HTC/ GOx/nafion $\left(100-1500 \mu \mathrm{mol} \mathrm{L}^{-1}\right)$. The sensitivity of GCE/NS-C/GOx/nafion is $0.0554 \mu \mathrm{A} \mathrm{cm}^{-2} \mu \mathrm{mol}^{-1} \mathrm{~L}$, which is better than that of GCE/HTC/GOx/nafion $\left(0.0099 \mu \mathrm{A} \mathrm{cm}^{-2} \mu \mathrm{mol}^{-1} \mathrm{~L}\right)$. The detection limit is 1.77 $\mu \mathrm{mol} \mathrm{L}{ }^{-1}(\mathrm{~S} / \mathrm{N}=3)$, which is lower than those of enzymatic biosensors such as GCE/HTC/GOx/nafion $\left(20 \mu \mathrm{mol} \mathrm{L}^{-1}\right)$, GOD/graphene/CS/GCE $\left(20 \mu \mathrm{mol} \mathrm{L}^{-1}\right)$ [52] and GOD/ mesocellular carbon foam/Nafion $\left(70 \mu \mathrm{mol} \mathrm{L}^{-1}\right)$ [57].

\section{CONCLUSIONS}

This study proposed a simple and efficient method for preparation of $\mathrm{N}$ and $\mathrm{S}$ dual-doped hydrothermal carbon. The results confirm that the sulfur and nitrogen elements are doped into the carbon frameworks, which further facilitates the interfacial electron transfer of the redox probe to electrode. Electrochemical performance shows that the GCE/NS-C/nafion modified electrode has a lower charge transfer resistance $(46 \Omega)$, and faster electron transfer rate. The lower magnitude of $K_{\mathrm{m}}$ represents that the GOx immobilized on the NS-C has a high affinity and activity to the glucose in the enzymatic reaction. Because of the excellent electrochemical properties, the NS-C based biosensor shows a good sensitivity (0.0554 $\left.\mu \mathrm{A} \mathrm{cm}^{-2} \mu \mathrm{mol}^{-1} \mathrm{~L}\right)$, wide linear range $\left(50-2500 \mu \mathrm{mol} \mathrm{L}^{-1}\right)$ and low detection limit $\left(1.77 \mu \mathrm{mol} \mathrm{L}^{-1}\right)$ for the detection of glucose. All the presented results indicate that the NS$\mathrm{C}$ can reach a low charge transfer resistance. This study would pave the way for the application of high performance hydrothermal carbon-based biosensor.

Received 28 June 2017; accepted 21 August 2017; published online 13 October 2017

1 Li X, Zhang G, Bai X, et al. Highly conducting graphene sheets and Langmuir-Blodgett films. Nat Nanotech, 2008, 3: 538-542

2 Ge J, Lan M, Liu W, et al. Graphene quantum dots as efficient, metal-free, visible-light-active photocatalysts. Sci China Mater, 2016, 59: 12-19

3 Shokrieh MM, Saeedi A, Chitsazzadeh M. Mechanical properties of multi-walled carbon nanotube/polyester nanocomposites. J Nanostruct Chem, 2013, 3: 20

4 Guo Z, Xiao Z, Ren G, et al. Natural tea-leaf-derived, ternarydoped $3 \mathrm{D}$ porous carbon as a high-performance electrocatalyst for the oxygen reduction reaction. Nano Res, 2016, 9: 1244-1255

5 Li Y, Zhou W, Wang H, et al. An oxygen reduction electrocatalyst based on carbon nanotube-graphene complexes. Nat Nanotech, 2012, 7: 394-400

6 Chen Y, Shi J. Mesoporous carbon biomaterials. Sci China Mater, 2015, 58: 241-257

7 Yang W, Ratinac KR, Ringer SP, et al. Carbon nanomaterials in biosensors: should you use nanotubes or graphene? Angew Chem Int Ed, 2010, 49: 2114-2138

8 Suk JW, Kitt A, Magnuson CW, et al. Transfer of CVD-grown monolayer graphene onto arbitrary substrates. ACS Nano, 2011, 5: 6916-6924

9 Yang CM, Weidenthaler C, Spliethoff B, et al. Facile template synthesis of ordered mesoporous carbon with polypyrrole as car- 
bon precursor. Chem Mater, 2005, 17: 355-358

10 Zhao J, Su Y, Yang Z, et al. Arc synthesis of double-walled carbon nanotubes in low pressure air and their superior field emission properties. Carbon, 2013, 58: 92-98

11 Fitzer E, Schaefer W, Yamada S. The formation of glasslike carbon by pyrolysis of polyfurfuryl alcohol and phenolic resin. Carbon, 1969, 7: 643-648

12 Chemat F, Vian MA, Cravotto G. Green extraction of natura products: concept and principles. Int J Mol Sci, 2012, 13: 86158627

13 Lu Z, Wu X, Jiang M, et al. Transition metal oxides/hydroxides nanoarrays for aqueous electrochemical energy storage systems. Sci China Mater, 2014, 57: 59-69

14 Sun X, Li Y. Colloidal carbon spheres and their core/shell structures with noble-metal nanoparticles. Angew Chem Int Ed, 2004, 43: 597-601

15 Sevilla M, Fuertes AB. The production of carbon materials by hydrothermal carbonization of cellulose. Carbon, 2009, 47: 22812289

16 Yang L, Yang J, Xu B, et al. Facile preparation of molecularly imprinted polypyrrole-graphene-multiwalled carbon nanotubes composite film modified electrode for rutin sensing. Talanta, 2016 , 161: 413-418

17 Razmi H, Mohammad-Rezaei R. Graphene quantum dots as a new substrate for immobilization and direct electrochemistry of glucose oxidase: application to sensitive glucose determination. Biosens Bioelectron, 2013, 41: 498-504

$18 \mathrm{Du} \mathrm{H}$, Ye J, Zhang J, et al. Graphene nanosheets modified glassy carbon electrode as a highly sensitive and selective voltammetric sensor for rutin. Electroanalysis, 2010, 22: 2399-2406

19 Song J, Yang J, Zeng J, et al. Acetylene black nanoparticle-modified electrode as an electrochemical sensor for rapid determination of rutin. Microchim Acta, 2010, 171: 283-287

20 Cao H, Ye D, Zhao Q, et al. A novel aptasensor based on MUC-1 conjugated CNSs for ultrasensitive detection of tumor cells. Analyst, 2014, 139: 4917-4923

21 Hong F, You S, Wei M, et al. MGRA: motion gesture recognition via accelerometer. Sensors, 2016, 16: 530

22 Chen G, Liu Y, Liu Y, et al. Nitrogen and sulfur dual-doped graphene for glucose biosensor application. J Electroanal Chem, 2015, 738: $100-107$

23 Geng D, Yang S, Zhang Y, et al. Nitrogen doping effects on the structure of graphene. Appl Surf Sci, 2011, 257: 9193-9198

24 Wang C, Zhou Y, Sun L, et al. Sustainable synthesis of phosphorusand nitrogen-co-doped porous carbons with tunable surface properties for supercapacitors. J Power Sources, 2013, 239: 81-88

25 Kalijadis A, Đorđević J, Trtić-Petrović T, et al. Preparation of boron-doped hydrothermal carbon from glucose for carbon paste electrode. Carbon, 2015, 95: 42-50

26 Sun M, Zhang G, Liu $\mathrm{H}$, et al. $\alpha$ - and $\gamma-\mathrm{Fe}_{2} \mathrm{O}_{3}$ nanoparticle/nitrogen doped carbon nanotube catalysts for high-performance oxygen reduction reaction. Sci China Mater, 2015, 58: 683-692

27 Yang $\mathrm{P}$, Zhou L, Zhang S, et al. Facile synthesis and photoluminescence mechanism of graphene quantum dots. J Appl Phys, 2014, 116: 244306

28 Niu S, Lv W, Zhou G, et al. N and S co-doped porous carbon spheres prepared using L-cysteine as a dual functional agent for high-performance lithium-sulfur batteries. Chem Commun, 2015, 51: $17720-17723$

29 Wohlgemuth SA, Vilela F, Titirici MM, et al. A one-pot hydro- thermal synthesis of tunable dual heteroatom-doped carbon microspheres. Green Chem, 2012, 14: 741-749

30 Wang X, Li X, Zhang L, et al. N-doping of graphene through electrothermal reactions with ammonia. Science, 2009, 324: 768771

31 Wang Y, Shao Y, Matson DW, et al. Nitrogen-doped graphene and its application in electrochemical biosensing. ACS Nano, 2010, 4: 1790-1798

32 Ji H, Zhou F, Gu J, et al. Nitrogen-doped carbon dots as a new substrate for sensitive glucose determination. Sensors, 2016, 16: 630

33 Zhang C, Yang QH. Packing sulfur into carbon framework for high volumetric performance lithium-sulfur batteries. Sci China Mater, 2015, 58: 349-354

34 Kim H, Lee K, Woo SI, et al. On the mechanism of enhanced oxygen reduction reaction in nitrogen-doped graphene nanoribbons. Phys Chem Chem Phys, 2011, 13: 17505-17510

35 Tian Y, Ma Y, Liu H, et al. One-step and rapid synthesis of nitrogen and sulfur co-doped graphene for hydrogen peroxide and glucose sensing. J ElectroAnal Chem, 2015, 742: 8-14

36 Fang $\mathrm{Y}, \mathrm{Gu}$ D, Zou Y, et al. A low-concentration hydrothermal synthesis of biocompatible ordered mesoporous carbon nanospheres with tunable and uniform size. Angew Chem, 2010, 122: 8159-8163

37 Choi $\mathrm{CH}$, Chung MW, Park SH, et al. Additional doping of phosphorus and/or sulfur into nitrogen-doped carbon for efficient oxygen reduction reaction in acidic media. Phys Chem Chem Phys, 2013, 15: 1802-1805

38 Zhao L, Baccile N, Gross S, et al. Sustainable nitrogen-doped carbonaceous materials from biomass derivatives. Carbon, 2010, 48: $3778-3787$

39 White RJ, Antonietti M, Titirici MM. Naturally inspired nitrogen doped porous carbon. J Mater Chem, 2009, 19: 8645-8650

40 Lei Y, Shi Q, Han C, et al. N-doped graphene grown on silk cocoon-derived interconnected carbon fibers for oxygen reduction reaction and photocatalytic hydrogen production. Nano Res, 2016, 9: 2498-2509

41 Sun F, Wang J, Chen $\mathrm{H}$, et al. High efficiency immobilization of sulfur on nitrogen-enriched mesoporous carbons for Li-S batteries. ACS Appl Mater Interfaces, 2013, 5: 5630-5638

42 Yang Z, Yao Z, Li G, et al. Sulfur-doped graphene as an efficient metal-free cathode catalyst for oxygen reduction. ACS Nano, 2012, 6: 205-211

43 Kiciński W, Szala M, Bystrzejewski M. Sulfur-doped porous carbons: synthesis and applications. Carbon, 2014, 68: 1-32

$44 \mathrm{Gu}$ W, Sevilla M, Magasinski A, et al. Sulfur-containing activated carbons with greatly reduced content of bottle neck pores for double-layer capacitors: a case study for pseudocapacitance detection. Energy Environ Sci, 2013, 6: 2465-2476

45 Ai W, Luo Z, Jiang J, et al. Nitrogen and sulfur codoped graphene: multifunctional electrode materials for high-performance Li-Ion batteries and oxygen reduction reaction. Adv Mater, 2014, 26: 6186-6192

46 Niu S, Lv W, Zhang C, et al. One-pot self-assembly of graphene/ carbon nanotube/sulfur hybrid with three dimensionally interconnected structure for lithium-sulfur batteries. J Power Sources, 2015, 295: 182-189

47 Ghica ME, Brett CMA. A glucose biosensor using methyl viologen redox mediator on carbon film electrodes. Anal Chim Acta, 2005, 532: $145-151$ 
48 Shervedani RK, Mehrjardi AH, Zamiri N. A novel method for glucose determination based on electrochemical impedance spectroscopy using glucose oxidase self-assembled biosensor. Bioelectrochemistry, 2006, 69: 201-208

49 Ramanavicius A, Genys P, Oztekin Y, et al. Evaluation of the redox mediating properties of 1,10-phenanthroline-5,6-dione for glucose oxidase modified graphite electrodes. J Electrochem Soc, 2014, 161: B31-B33

50 Ciureanu M, Wang H, Qi Z. Electrochemical impedance study of membrane-electrode assemblies in PEM fuel cells. II. Electrooxidation of $\mathrm{H}_{2}$ and $\mathrm{H}_{2} /$ Co mixtures on $\mathrm{Pt} / \mathrm{Ru}$-based gas-diffusion electrodes. J Phys Chem B, 1999, 103: 9645-9657

51 Zhang Y, Kang Z, Yan X, et al. ZnO nanostructures in enzyme biosensors. Sci China Mater, 2015, 58: 60-76

52 Kang X, Wang J, Wu H, et al. Glucose oxidase-graphene-chitosan modified electrode for direct electrochemistry and glucose sensing. Biosens Bioelectron, 2009, 25: 901-905

53 Deng S, Jian G, Lei J, et al. A glucose biosensor based on direct electrochemistry of glucose oxidase immobilized on nitrogendoped carbon nanotubes. Biosens Bioelectron, 2009, 25: 373-377

54 Qiu JD, Huang J, Liang RP. Nanocomposite film based on graphene oxide for high performance flexible glucose biosensor. Sensors Actuators B-Chem, 2011, 160: 287-294

55 Li J, Tan SN, Ge H. Silica sol-gel immobilized amperometric biosensor for hydrogen peroxide. Anal Chim Acta, 1996, 335: $137-$ 145

56 Liang RP, Fan LX, Wang R, et al. One-step electrochemically deposited nanocomposite film of CS-Fc/MWNTs/GOD for glucose biosensor application. Electroanalysis, 2010, 21: 1685-1691

57 Lee D, Lee J, Kim J, et al. Simple fabrication of a highly sensitive and fast glucose biosensor using enzymes immobilized in mesocellular carbon foam. Adv Mater, 2005, 17: 2828-2833

Acknowledgements This work was supported by the National Basic Research Program of China (973 Program, 2014CB931900), UCAS Young Teacher Research Fund (Y55103NY00, Y55103EY00, and Y25102TN00), Beijing Natural Science Foundation (Z160002), and The Chinese Academy of Sciences Key Project Foundation (KFZD-SW-202).

Author contributions Liu J and Chen C designed the project and guide this work; $\mathrm{Hu} \mathrm{B}$ performed the experiments; $\mathrm{Hu} \mathrm{B}$ wrote the paper with support from Liu J and Chen C. All authors contributed to the general discussion.

Conflict of interest The authors declare that they have no conflict of interest.

Supplementary information Supporting data are available in the online version of the paper. 


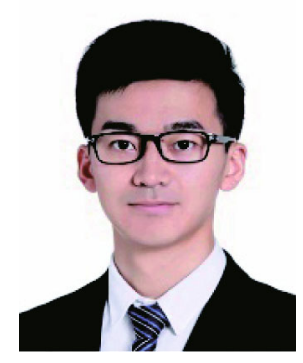

Botao Hu received his bachelor degree from Anhui Normal University. He is now a master candidate at the University of Chinese Academy of Sciences (UCAS) and his research is focused on the carbon materials.

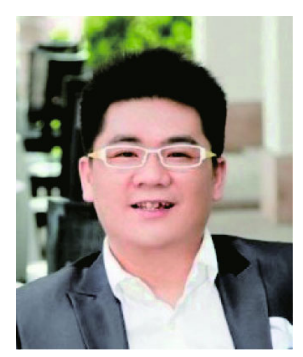

Jen-Tsai Liu is an associate professor at the University of Chinese Academy of Sciences. He received his bachelor degree in 2002 and master degree in 2004 from I-Shou University, and his $\mathrm{PhD}$ in 2010 in chemical and materials engineering from Central University, Taiwan. His current research has been mainly focused on biosensors and bioelectrics.

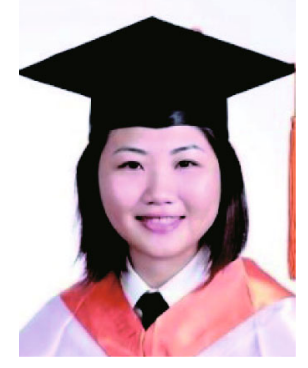

Ching-Jung Chen is an associate professor at the University of Chinese Academy of Sciences. She received his bachelor degree in 2002 and master degree in 2004 from I-Shou University, and her PhD in 2010 in electrical engineering from Central University, Taiwan. Her current research has been mainly focused on biosensors, bioelectrics and biomaterials.

\section{一步水热法合成超低电荷转移阻抗的碳材料及其葡萄糖检测性能研究}

胡博韬, 刘仁材 ${ }^{*}$, 陈靖容 ${ }^{2 *}$, 赵湛 ${ }^{2,3}$, 张淑真 $^{4}$, 康沛伦 ${ }^{5}$

摘要 水热碳材料具有较好的水溶性, 但是通常表现为绝缘性, 因此提高水热碳材料的导电性仍然是一个重大挑战. 化学掺杂已经被证实 能够显著提高碳材料的导电性, 但目前尚没有一种简单且绿色的方法制备高灵敏度水热碳基的电化学传感器. 本文在水热反应体系中用 L-半胱氨酸和葡萄糖合成了超低电子转移阻抗的氮硫掺杂碳材料, 随后分析了材料的形貌、结构和电化学性质. 氮硫掺杂碳修饰电极电 子转移阻抗 $(46 \Omega)$ 大约是非掺杂碳修饰电极 $(476 \Omega)$ 的 $1 / 10$. 氮硫掺杂碳材料制备的葡萄糖传感器具有较宽线性范围 $\left(50-2500 \mu \mathrm{mol} \mathrm{L}{ }^{-1}\right)$, 低的检测限 $\left(1.77 \mu \mathrm{mol} \mathrm{L}^{-1}, \mathrm{~S} / \mathrm{N}=3\right)$ 和高的灵敏度 $\left(0.0554 \mu \mathrm{A} \mathrm{cm}^{-2} \mu \mathrm{mol}^{-1} \mathrm{~L}\right)$. GCE/NS-C/GOx/nafion电极的米氏常数为 $0.769 \mathrm{mmol} \mathrm{L}$, 表 明NS-C负载的葡萄糖氧化酶 (GOx) 对葡萄糖具有较高亲和力. 本研究提出以水热法合成具有高电导性的碳材料, 并应用于高性能的葡萄 糖传感器. 